\title{
Stage Performance and Musical Analysis of Haacaaluu Hundeessaa Works by using Sentiment Analysis Techniques
}

\author{
Gemechu Boche Beshana
}

Wollega University, Institute of Engineering \& Technology, Department of Information Technology, Ethiopia

\begin{abstract}
Article Info

Volume 7, Issue 6

Page Number: 124-128

Publication Issue :

November-December-2021

\section{Article History}

Accepted : 10 Nov 2021

Published : 30 Nov 2021

This research is initiated to analysis the stage performance and musical analysis of Haacaaluu Hundeessaa works on Afaan oromoo reviews text collected from social Medias by applying the concept of sentiment analysis techniques. The data (reviews) were collected manually from social media on Haacaaluu Hundeessaa musical works. Haacaaluu Hundeessaa is Oromo singer, songwriter, civil rights activist and his being a voice his people. He is the most famous young singer, hero and icon of Oromo musician. From his musical works Sanyii Mootii(Race of the King), Waa'ee Keenyaa(Our Plight), Maalan Jira(What existence is mine), JIRTUU? are the most popular known in Oromo peoples as well as nation and nationality of Ethiopia. From Hacaaluu musical works, the researcher considered reviews (opinions) afaan oromoo text data on his single sang "JIRTUU?" to analysis stage performance of Haacaaluu Hundeessaa's. The researcher inspires to use this single sang because; reviews (comments) are easier to access, available on you tube channel, extensive in size relatively from other his songs from social media. Additionally this song was broadcast live by Oromia Broadcasting Network and other Medias on different stage. Opinion lexicon approach with contextual valence shifter is used for analyzing opinions (comments) given on stage performance of Haacaaluu Hundeessaa works. Totally 18,687 reviews opinions or sentences were collected for experimentations to analysis stage performance and musical works of Haacaaluu Hundeessaa. Accordingly our result indicates around 99.52 percents peoples likes the stage performance and musical works of Hacaaluu Hundeessaa. From the results researcher observed Haacaaluu Hundeessaa has good performer with sing emotional and physically when he sing on the stages. In future works, further research needs to study others musical works of Hacaaluu Hundeessaa.
\end{abstract}

Keywords : Afaan Oromoo Opinions, Haacaaluu Hundeessaa, Musical Analysis, sentiment analysis, Stage Performance. 


\section{INTRODUCTION}

Stage performance is an essential part of music making on stage that may engage and affect the audiences. When playing a piece, expert performers shape various parameters (tempo, timing, dynamics, intonation, articulation, etc.) in ways that are not prescribed by the notated score, in this way producing an expressive rendition that brings out dramatic, affective, and emotional qualities (Leon and Dirk, 1999). Given the central importance of this skill for many kinds of music, stage performance has become an important research topic for disciplines .This paper focuses on the stage performance and musical analysis of Haacaaluu Hundeessaa works on afaan oromo reviews text collected from social Medias by applying the concept of sentiment analysis techniques.

Haacaaluu Hundeessaa was born in $\underline{\text { Ambo in Oromia }}$ Region, Ethiopia, to Gudatu Hora and Hundeessaa Bonsa in 1986 (BBC, 2020). His family is from the Oromo ethnic group. Haacaaluu Hundeessaa grew up singing in school clubs and tending cattle. In 2003, at the age of 17, he was arrested for taking part in protests. He was imprisoned at Karchale Ambo for five years and later released in 2008. He was married to Fantu Demisse, with whom he has three children (BBC, 2020). Haacaaluu Hundeessaa composed the melodies and wrote most of the lyrics of his first album while he was in prison. The album, Sanyii Mootii, was released in 2009. In 2013, he toured the United States and released his second album, Waa'ee Keenyaa, which was the number one best-selling African music album on Amazon Music ((BBC News,2020)

Haacaaluu Hundeessaa's protest songs unified the Oromo people, encouraging them to resist oppression. His songs have been closely linked with the anti-government resistance that started in 2015 and the 2016 Ethiopian protests. His "Maalan Jira"
(What existence is mine) concerned the displacement of Oromo people from Addis Ababa. Months after the single was released in June 2015, protests opposing the Addis Ababa Master Plan occurred throughout the Oromia Region. The song became an anthem for protesters as well as one of the most viewed Oromo music videos.

In December 2017, Haacaaluu sang entitled as "IIRTUU?" at a concert in Addis Ababa that raised funds for 700,000 Oromo who were displaced by ethnic violence in Somali region. The concert was broadcast live by Oromia Broadcasting Network (BBC, 2020).

Haacaaluu Hundeessaa 's songs captured Oromo hopes and frustrations. Haacaaluu Hundeessaa was the soundtrack of the Oromo revolution, a lyrical genius and an activist who embodied the hopes and aspirations of the Oromo public. Haacaaluu Hundeessaa was shot on the evening of 29 June 2020 at the Gelan Condominiums area in Addis Ababa. He was taken to Tirunesh Beijing General Hospital, where he died at age 34 years old (BBC, 2020).

Human beings have ability to think, understand, make decisions and give their view points on mostly everything. Having this reasoning and decision making ability, the sentiments of humans are effected by almost everything, May be positively or negatively. Sentiment Analysis (SA) is a process of automatic extraction of knowledge by means of opinion of others about some particular culture, product, topic or problem (Liu, 2012). Sentiment analysis is a very active field of research. It also includes the study of identification of sentiments expressed towards music's in general or specific musical works of one artist's characteristics such as performance on with the objective of discovering likes and dislikes of the audiences. Stage performance make some people leave their seat and start dancing, on the other hand some music may even make some people cry out their 
heart (Rothstein, 1995). Some music pieces make a person happy, gushy and think about their romantic partners. Some music pieces provide feeling of calmness and peace.Not everyone takes the music same way. For some people a song may generate happy feeling whereas for some it may evoke negative feelings.

The stage performance of the artist has the ability to influence the behavior of the person. Haacaalua Hundeessaa is one of oromo m Musician who wasn't afraid to anyone to express his feeling on invited stages. His works can be good example likes sang "JIRTUU" in front of Eritrean President Isaias Afwerki, Ethiopian Prime Minister Dr. Abiy Ahmed and thousands of people at the Millennium Hall he declares without afraid about Oromo who were displaced by ethnic violence in Somali region. From his works others example can be at adawa day celerebration in ethipia at masqal square addis ababa he declare the role of oromo and nation and nationality of Ethiopia to fight etaly.

Therefore, this research work is the study of people's opinions, attitudes and emotions towards stage performance and musical works of Haacaaluu Hundeessaa 's works. Opinions are essential to almost all human activities because they are key influencers of behaviors (Selama, 2010). So the ability to automatically extract and analysis opinions on Haacaaluu Hundeessaa works would be hugely helpful to individuals, artists, nations and nationalities of Ethiopia peoples and other opinions make a decision. Those analyzed opinions can be used as an additional information source and document base to explore feature analysis for Haacaaluu Hundeessaa's works.

\section{Hachalu Hundessa Musical Works}

Hachalu was born in 1986 in Ambo -a city about $100 \mathrm{~km}$ west of the capital, Addis Ababa, Ethiopia
(BBC, 2020). At the age of 17 in 2003, Haacaaluu was imprisoned for five years for his political activities. His father kept his morale high in prison, telling him during visits that "prison makes a man stronger". Haacaaluu became increasingly politicized in prison, as he increased his knowledge about Ethiopia's history, including its rule by emperors and autocrats. Whilst incarcerated in Ambo prison he also developed his music skills.

During his time in jail, he wrote nine songs and released his first album Sanyii Mootii (Race of the King) in 2009, a year after walking free. The album turned him into a music star, and a political symbol of the Oromo people's aspirations. His second album Waa'ee Keenya (Our Plight) was released in 2013 while he was on a tour in the US. It became the bestselling African album on Amazon at the time. Two years later, he released a powerful single, Maalan Jira? (What existence is mine?), referring to the eviction of Oromos from Addis Ababa and its surrounding areas, after the government decided to expand the boundaries of the city.

Two months after Mr Abiy took office, Haacaaluu was invited by the government to perform at a concert held in honor of Eritrea's President Isaias Afeworki, who was visiting Ethiopia for the first time since the end of a border war between the two neighboring states. Haacaaluu proved to be as independent and fearless as ever, singing single song "JIRTUU?" about the need to achieve justice for people who had been killed in conflict in eastern Ethiopia between the Oromo and Somali ethnic groups, and questioning how a concert could be held when families were grieving. This works makes more it increased his popularity. 


\section{MATERIAL AND METHODS}

\subsection{Data sets}

The datasets or reviews for conducting the experiment analysis are manually collected from social media likes YouTube channel on the musical works of Hacaaluu Hundeessaa. For this study, 18,687 music reviews sentiments or sentences were collected for experimentations to analysis stage performance and musical works of Haacaaluu Hundeessaa. Haacaaluu Hundeessaa has 2 albums of song and 2 single songs. His first album Sanyii Mootii (Race of the King) in 2009 and His second album Waa'ee Keenya (Our Plight) was released in 2013. Two years later, he released a powerful single, Maalan Jira? (What existence is mine?. Hacaaluu Hundeessaa's sang a powerful single "JIRTUU?" at a concert in Addis Ababa that raised funds for 700,000 Oromo who were displaced by ethnic violence in Somali region. The concert was broadcast live by Oromia Broadcasting Network. From Haacaaluu Hundeessaa's the researcher considered reviews data on his single sang "JIRTU" to analysis stage performance of Haacaaluu Hundeessaa's. The researcher motivated to use this single sang because; reviews (comments) are easier to access, available on you tube channel.

\subsection{Methodology}

There are three main classification levels in SA: document-level, sentence-level, and aspect-level SA. Therefore, in this study we select document level sentiment analysis to analysis stage performance of Hacaaluu Hundeessaa's works sing at concert mullunium hall on song "JIRTUU?" There are different types of approaches in sentiment analysis like machine learning, lexicon-based, statistical and rule-based approaches (Liu, 2012). Therefore, a lexicon based sentiment analysis approach employed as a development method. Opinion lexicon approach with contextual valence shifter is used for analyzing opinions (comments) given on stage performance of Hacaaluu Hundeessaa works. When using this technique, it is comparatively easy to incorporate contextual valence shifters. As a result, the opinionated review text passes through components of the model such as: text preprocessing, sentiment terms detection, polarity propagation, review's polarity weight calculation and reviews polarity classification components for polarity analysis.

\section{DISCUSSION AND RESULTS}

To analysis our study, we used Afaan Oromo reviews (comments) obtained from YouTube channel on musical works of Hacaaluu Hundeessaa's entitled as "JIRTUU? . All of the datasets (social media posts/comments) used for conducting the experiment analysis from YouTube channel on the musical works of Hacaaluu Hundeessaa's on the stages such as at millennium hall when he declare about Oromo who were displaced by ethnic violence in Somali region , on the stage of masqal square ,addis ababa when he declare the role of oromo and nation and nationality of Ethiopia on Adawa to fight italy. Generally, a total of 18,876 reviews (comments) are collected from all the sources described above.

The objective of the study was to analysis stage performance of hachalu hundessa's on musical works by using sentiment analysis depend on opinions given from his audiences. opinion lexicon approach with contextual valence shifter are used for analyzing opinions (comments) given on stage performance of Hacaaluu Hundeessaa's musical works.

We have developed lexicon which is a keyword of opinion words which contains positive and the negative words. Negations should be handled appropriately to get the contextual information of a sentence. If the opinion word is in negative relation, then its priority score is reversed for negation handling purpose. Finally, the following results obtained from the techniques and method of researcher used. 


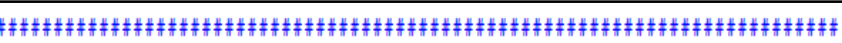
Sentiment (Opinion) Analysis From Afaan Oromoo Reviews Text

on Stage Performance and Musical Analysis of Hachaaluu Hundeessaa Works:

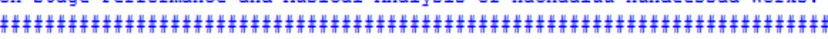
Total number of over all opinionated(Conments) Text :18786

Total number of Positive comments :18697=99.52 \%요

Total number of Negative comments $: 89=0.47$ \%

The document classified into positive corment, in percent : $99.52 \%$

From the above result we obtained results from 18,786 total opinions text 18,697 were classified into positive and 89 classified into negative. That means in percent 99.52 percent peoples likes while $0.47 \%$ percent did not like the stage performance and musical works of Hacaaluu Hundeessaa's.

Our result analysis indicates around 99.52 percent likes the stage performance and musical works of Hacaaluu Hundeessaa's. From the reviews(Comments) the researcher observed Hacaaluu Hundeessaa has good performer such as he sing with emotion and fearless, Express his emotions physically, express his feeling and justice on invited stages, contact aye audience and etc, when he sing on stage makes Hacaaluu Hundeessaa model artist and liked by his audiences.

\section{CONCLUSIONS}

This study investigates to analysis the stage performance and musical analysis of Haacaaluu Hundeessaa works based on afaan oromo reviews text collected from social Medias by applying the concept of sentiment analysis techniques. Generally, a total of 18,876 reviews (comments) are collected from you Tube channel of Oromia broad cast network on the musical works of Hacaaluu Hundeessaa . Accordingly our result indicates around 99.52 percents likes the stage performance and musical works of Haacaaluu Hundeessaa .

In future work, the researcher plan work to other works and give directions of Hacaaluu Hundeessaa likes forms and contents of Haacaaluu Hundeessaa lyrics, culture and political Discourse in Hacaaluu Hundeessaa lyrics, the role of Haacaaluu Hundeessaa struggle and equity and stylistics' analysis of Hacaaluu Hundeessaa lyrics. Additionally this works can be used as an additional information source and document base to explore feature analysis for Haacaaluu Hundeessaa works.

\section{Author profile}

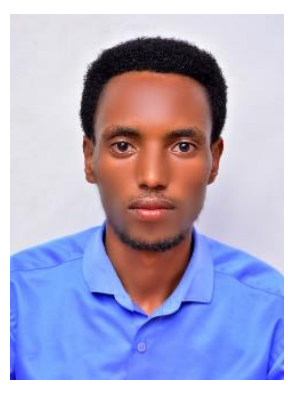

Gemechu Boche Beshana (MSc in computer science) working as senior lecturer and Head of department in Department of Information Technology, and Wollega University, Nekemte, Ethiopia

\section{REFERENCES}

[1]. BBC. (2020). news.

[2]. Kennedy, A., \& Inkpen, D. (2006). Sentiment Classification of Movie and Product Reviews using Contextual Valence Shifters. Journal of Computational Intelligence .

[3]. eon and Dirk. (1999). Resonance in. Journal of New Music , 43-66.

[4]. Liu, B. (2012). Sentiment Analysis and Opinion Mining. Morgan and Claypool.

[5]. Rothstein. (1995). "Analysis and the Act of Performance”. . Cambridge University Press , 28.

[6]. Selama. (2010). Sentiment Mining Model for Opinionated Amharic Texts. Addis Ababa University, Ethiopia, Msc Thesis , 1-6.

\section{Cite this article as :}

Gemechu Boche Beshana, "Stage Performance and Musical Analysis of Haacaaluu Hundeessaa Works by using Sentiment Analysis Techniques", International Journal of Scientific Research in Computer Science, Engineering and Information Technology (IJSRCSEIT), ISSN : 2456-3307, Volume 7 Issue 6, pp. 124-128, November-December 2021. Available at doi : https://doi.org/10.32628/CSEIT217224 Journal URL : https://ijsrcseit.com/CSEIT217224 